\title{
La unión entre personas del mismo género: ¿cuán importantes son los textos y las instituciones?
}

\author{
Virgílio Afonso da Silva*
}

Recepción: 18/11/14.

Revisiones: 2/3/2015.

Aceptación: 19/3/15.

\begin{abstract}
Resumen: A la par de la tendencia internacional, el Supremo Tribunal Federal (STF) de Brasil ha decidido, por unanimidad, permitir que dos personas del mismo género celebren una unión de hecho. En este texto, defiendo que, aunque haya alcanzado importantes e innegables progresos sustantivos, el fallo del STF sobre la unión de hecho entre personas del mismo género suscita diversas objeciones formales e institucionales. Por un lado, en el ámbito normativo, Brasil tiene la regulación sobre matrimonio y unión de hecho más específica en lo que se refiere al género de todos los países aquí analizados. Por otro lado, en el ámbito institucional, Brasil es el único país en el cual el
\end{abstract}

* Profesor Catedrático de la Facultad de Derecho de la Universidad de São Paulo. Email: vas@usp.br

Este artículo fue parcialmente escrito durante mi estadía de investigación en la Universidad Humboldt de Berlín. Quiero expresar mi agradecimiento a Dieter Grimm, mi anfitrión académico en Berlín, y a la Fundación Humboldt, que me concedió una Humboldt Research Fellowship for Experienced Researchers. También me gustaría agradecer a Kai Möller, David Bilchitz, Conrado H. Mendes, Octávio Ferraz, Carlos Bernal Pulido, Ligia Fabris Campos y Daniel Sarmento por sus comentarios a una versión preliminar de este artículo. Finalmente, me gustaría agradecer a Paula Gaido por haber sugerido mi nombre para colaborar, y a los comentarios de Sebastián Elías y el referee anónimo de la revista. 
poder legislativo fue completamente ignorado durante todo el proceso. Si el STF hubiese tomado en serio el valor del texto legal y de las instituciones, el desenlace probablemente habría sido mucho mejor para la Corte en sí, para el Congreso, para la sociedad civil como un todo y especialmente para las parejas de mismo género, que aún hoy no tienen los mismos derechos atribuidos a las parejas de género diferente.

Palabras clave: género, unión civil, marriage.

\begin{abstract}
Together with the international trend, the Federal Supreme Court (STF) of Brazil has decided, unanimously, to allow the fact that two people of the same gender can celebrate a civil union. In this paper, I affirm that although the sentence of the STF has reached important and undeniable substantive progresses on the civil union between people of the same gender, it brings different substantive formal and institutional objections. On one hand, on the normative scope, Brazil has the most specific regulation on marriage and civil union referred to gender matters of all the states analyzed here. On the other hand, on the institutional scope, Brazil is the only country in which the legislative power was completely ignored during the whole process. If the STF had taken seriously the value of the legal text and the institutions, the outcome probably would have been much better for the Court itself, for he Congress, for the civil society as a whole and specially for the same gender couples, who still today do not have the same rights that the couples of the different gender have.
\end{abstract}

Key words: gender, civil union, marriage.

\title{
I. Introducción
}

A la par de la tendencia internacional hacia una expansión de los conceptos de matrimonio y unión de hecho que incluya a las parejas de un mismo género, el Supremo Tribunal Federal ha decidido, por unanimidad, que el artículo 1723 del Código Civil brasileño, el cual define el concepto de unión de hecho como la unión entre un hombre y una mujer, debe interpretarse de tal forma que permita que dos personas del mismo género celebren una unión de hecho. En este texto, mi intención es analizar ese fallo. No pretendo, sin embargo, analizar los aspectos sustantivos del matrimonio entre personas del 
mismo género, ya sea en abstracto o en el caso concreto de Brasil. El enfoque del presente artículo es más bien formal y procedimental. Defiendo que, desde una perspectiva formal y procedimental, el caso brasileño se distingue de las demás experiencias de ampliación del concepto de matrimonio o de unión de hecho en las últimas décadas y presenta varias cuestiones problemáticas.

Se debe enfatizar, desde ya, que el hecho de que el enfoque se haya desplazado de un análisis sustantivo a uno formal y procedimental no implica, de cualquier manera, una estrategia elaborada para atacar los matrimonios entre personas del mismo género por otros medios. Al contrario, quedará evidente a lo largo de este artículo que, en lo que se refiere al desenlace sustantivo del fallo brasileño, no hay divergencias relevantes entre mi posición sobre el tema y la que suscribe el Supremo Tribunal Federal. En realidad, si hay alguna discrepancia, es porque considero que no solo la unión de hecho, sino también el matrimonio debería haber sido ampliado a fin de incluir a las parejas del mismo género ${ }^{1}$. Desde una perspectiva sustantiva, considero que limitar tanto el matrimonio como la unión de hecho a parejas de género diferente es incompatible con diversos principios constitucionales, de los cuales el más obvio es el de la igualdad ante la ley. Dicho eso, acepto, como premisas sustantivas del presente artículo, los principales argumentos sustantivos presentados en decisiones tomadas por parlamentos, así como en los fallos de algunas cortes constitucionales en los últimos años.

A fin de sustentar que el caso brasileño, no obstante exhibir semejanzas sustanciales, se distingue de los casos de otros países, este artículo ha sido organizado de la siguiente manera: en los tópicos 2 y 3 , presento un breve resumen de las acciones de inconstitucionalidad presentadas y del fallo del Supremo Tribunal Federal. Luego, en los tópicos 4 a 6, propongo establecer una conexión entre dos dicotomías: (1) parlamentos y cortes; y (2) normas e instituciones. A seguir, en el tópico 7, procuro analizar de qué manera el Supremo Tribunal Federal generalmente articula la idea de deferencia. En el tópico 8 me valgo

1 Con todas las consecuencias que un matrimonio tradicional implica, especialmente la posibilidad de adopción. 
de ejemplos de derecho comparado, especialmente de África del Sur y de Colombia, para ofrecer una alternativa al discurso de deferencia puramente retórico de esa Corte. Los ejemplos de derecho comparado demuestran que la estrategia utilizada por el Supremo Tribunal Federal - la cual denomino "atajo institucional" (institutional bypass) - no solo era innecesaria, sino que también generó diversos problemas que analizo en el tópico 9. El tópico 10 es la conclusión del artículo.

\section{Las acciones de inconstitucionalidad}

Dos acciones de control concentrado de constitucionalidad distintas, pero muy semejantes, sobre uniones de hecho entre personas del mismo género fueron presentadas ante el Supremo Tribunal Federal. La primera de ellas, la Acción de Incumplimiento de Precepto Fundamental 132 (ADPF 132), fue enjuiciada por el gobernador del estado de Río de Janeiro el 27 de febrero de 2008 y la segunda, la Acción Directa de Inconstitucionalidad 4277 (ADI 4277)², fue enjuiciada por la Fiscalía General de la República en 2 de julio de 2009. Debido a sus semejanzas, ambas fueron juzgadas conjuntamente.

En resumen, en las dos acciones se argumentaba que restringir la unión de hecho a parejas de género diferente es incompatible con varios principios constitucionales, en especial: la protección de la dignidad humana (artículo 1, apartado III de la Constitución Federal de Brasil), la prohibición de cualquier forma de prejuicio (artículo 3, apartado IV), la igualdad ante la ley (artículo 5, caput), la libertad (artículo 5, caput) y la seguridad jurídica (artículo 5, caput).

Las dos acciones también manejaban de modo semejante el hecho de que la Constitución brasileña estableciera explícitamente que las uniones de hecho existen entre "el hombre y la mujer" (artículo 226,

2 Para detalles sobre las diferentes acciones de control de constitucionalidad en Brasil, cf. Silva, V.A., "Supremo Tribunal Federal", en E. Ferrer MacGregor (org.), Crónica de tribunales constitucionales en Iberoamérica, Buenos Aires/México, Marcial Pons/UNAM, 2009, págs. 85-106. 
párrafo 3$)^{3}$. Defendían que esa disposición debería interpretarse "teleológicamente", con lo que se afirmaba, en síntesis, que como había sido incluida con el objetivo de expandir la protección de personas que prefirieran tan solo convivir, en lugar de casarse, sería contradictorio utilizarla ahora para restringir la protección de parejas únicamente porque el texto se refiere al "hombre y la mujer".

Además, el requirente de la ADI 4277 argumentaba que, como la acción trataba de varios derechos constitucionales básicos, no sería posible esperar hasta que la cuestión se resolviese por vía legislativa. De modo similar, la requirente de la ADPF 132 sostenía que la ausencia de regulación de la unión de hecho entre personas del mismo género debería ser sanada por medio de la aplicación (judicial) analógica del artículo 1723 del Código Civil brasileño, el cual regula la unión de hecho entre personas de género diferente.

\section{El fallo}

Redactar el resumen de un fallo del Supremo Tribunal Federal o encontrar su ratio decidendi es una tarea muy difícil. Debido al estilo de tomar decisiones mediante la declaración de votos en serie y dado que, en rigor, no hay una opinión de la corte, sino solo una secuencia de once votos escritos, es casi siempre difícil y muchas veces imposible identificar claramente cuáles fueron las razones subyacentes de un determinado fallo, si bien es posible llegar al resultado por medio de un esquema binario del tipo "constitucional/inconstitucional". Los únicos productos finales de ese proceso decisorio son el sumario (ementa) y la resolución (acórdão). El sumario es una síntesis del fallo (en general, no más que algunas frases). A su vez, la resolución es una especie de "resultado definitivo", un texto muy conciso (de uno o dos párrafos, en general) que indica si el fallo fue por unanimidad o

3 Constitución de Brasil, artículo 226, párrafo 3: "Para los efectos de la protección del Estado, se reconoce la unión de hecho entre el hombre y la mujer como entidad familiar, para lo cual la ley debe facilitar su conversión en matrimonio". 
por mayoría de votos y si la ley fue considerada parcial o totalmente constitucional o inconstitucional.

En el Supremo Tribunal Federal, las sesiones plenarias son, en general, "sesiones de lectura de votos", en vez de "sesiones deliberativas". Eso significa que, especialmente cuando el caso despierta gran interés, los once magistrados ya han redactado sus votos al abrirse la sesión. En otras palabras: los magistrados redactan sus votos sin conocer el voto del ponente (relator) o de cualquier otro magistrado ${ }^{4}$.

Por lo tanto, aunque dictada por unanimidad, el fallo con respecto a la unión de hecho entre personas del mismo género sigue ese modelo, lo que vuelve imposible identificar claramente sus razones subyacentes, aun cuando se pueda conocer el contenido del fallo por medio del resultado final, pues todos los magistrados votaron a favor de permitir la unión de hecho entre personas del mismo género en Brasil. En los párrafos que siguen, trataré de resumir los argumentos invocados por el ponente del pleito, el magistrado Ayres Britto, y a lo largo del artículo también mencionaré los argumentos de otros magistrados.

El magistrado Ayres Britto argumentó que el artículo 1723 del Código Civil brasileño (que regula las uniones de hecho en Brasil) debería ser objeto de una "interpretación conforme a la Constitución", lo que, en su opinión, implicaría prohibir cualquier interpretación que negase el status de familia a parejas del mismo género. Además, el reconocimiento de parejas del mismo género como entidades familiares debería seguir las mismas reglas y tener las mismas consecuencias que las uniones de hecho entre personas de género distinto ${ }^{5}$. Como ocurre frecuentemente en el Supremo Tribunal Federal, el voto del magistrado Ayres Britto se aproxima más a un raciocinio de estilo enciclopédico que a una resolución judicial. Después de dedicar varias páginas a la citación de filósofos y juristas (así como de poetas y compositores), el magistrado resume su justificación en las siguientes etapas: la

4 Cfr. Silva, V.A., "Deciding Without Deliberating", International Journal of Constitutional Law, 11, 2013, págs. 569-570.

5 Supremo Tribunal Federal, ADI4277/ADPF132, voto escrito del magistrado ponente (Ayres Britto), pág. 656 (el fallo está disponible en $<$ http:// www.stf.jus.br/portal/inteiroTeor/obterInteiroTeor.asp?id=628635>). 
constitución brasileña prohíbe expresamente cualquier tipo de prejuicio, incluso de género. En su opinión, de ahí se deduce que cualquier forma de prejuicio basada en la orientación sexual también debe considerarse constitucionalmente prohibida ${ }^{6}$. Acto seguido, analiza el concepto de familia. Su argumento es que la porción más importante del artículo 226 es su parte inicial ("La familia, base de la sociedad, goza de especial protección del Estado"), no sus párrafos. Por consiguiente, aunque los párrafos mencionen "hombre y mujer", la parte inicial se refiere únicamente a la "familia", y es la familia - y no uno u otro tipo de matrimonio o unión de hecho- la que goza de protección especial del Estado ${ }^{7}$. De acuerdo con el razonamiento del magistrado, la familia es un hecho cultural y no biológico. Por lo tanto, es irrelevante que sea constituida formal o informalmente y lo es aún más que se componga de parejas de igual o distinto género ${ }^{8}$. En otras palabras, el magistrado argumentó que el concepto de familia debería guiar la interpretación de los demás párrafos y artículos de ese capítulo de la Constitución, y no lo contrario.

Aunque las reclamaciones de los requirentes se refirieran al concepto de unión de hecho, el magistrado Ayres Britto prácticamente ignoró la disposición constitucional acerca del tema (artículo 226, párrafo 3). Se limitó a argumentar que dicha disposición no puede interpretarse de manera reduccionista ${ }^{9}$ y que, si bien la constitución menciona que la unión de hecho es entre un hombre y una mujer, no prohíbe otros tipos de unión de hecho que puedan aparecer en el futuro. En los tópicos siguientes, pretendo analizar el fallo del Supremo Tribunal Federal a fin de establecer una conexión entre dos dicotomías: (1) parlamentos y cortes; y (2) normas e instituciones.

\section{Parlamentos, cortes y constituciones}

Uno de los principales problemas procedimentales que subyacen tras el debate sobre el matrimonio o la unión de hecho entre personas del

${ }^{6}$ Ibidem, pág. 640.

7 Ibídem, pág. 644.

8 Ídem.

9 Ibídem, pág. 653. 
mismo género es una discusión sobre competencia y legitimidad. Esa discusión asume la forma de una dicotomía entre parlamentos y cortes: ¿la decisión acerca de la posibilidad de permitir que parejas del mismo género contraigan matrimonio o formen una unión de hecho debe ser tomada por el legislativo, por motivo de su pedigrí democrático, o se trata de una cuestión de interpretación constitucional y legal, así como de un problema de protección de un derecho de minorías, que no solo permite la actuación de las cortes, sino que exige su participación? ${ }^{10}$

Aunque dicho debate sea de una importancia fundamental, ha sido conducido sin tener en cuenta los textos constitucionales y sus contextos. La dicotomía parlamentos vs. cortes ignora el hecho de que, a depender, entre otras cosas, de si y cómo una determinada constitución define los conceptos de matrimonio o de unión de hecho, escoger una u otra vía institucional para ampliar esas definiciones de tal modo que abarquen a las parejas de personas del mismo género puede ser una cuestión que no admita una elección plenamente libre.

En este artículo, presupongo que existe una relación bastante directa entre la regulación constitucional del matrimonio (y de la unión de hecho) y la posibilidad de que las cortes decidan por sí solas si las parejas del mismo género pueden casarse o formar una unión de hecho. Esa relación puede establecerse de la siguiente manera: cuanto más detallada sea la regulación del tema y más específica en lo que se refiere al género, menos libertad tienen las cortes para resolver el asunto ellas mismas. Dos sencillos ejemplos son suficientes para ilustrar lo que eso significa.

La Constitución del país $A$ declara que "todos son iguales ante la ley" y no contiene ninguna regla con respecto al matrimonio o a la unión de hecho. Una ley ordinaria en el país $A$ (un

${ }^{10}$ No es necesario decir que esas dos alternativas (legislativo vs. corte) no son mutuamente excluyentes. En realidad, activistas y litigantes (en ambos los lados de la controversia) utilizan estratégicamente esas dos posibilidades institucionales. Sobre el caso de Brasil, cfr. Schulenberg, S. "Policy Stability without Policy: The Battle over Same-Sex Partnership Recognition in Brazil", in J. Pierceson et. al. (eds.), Same-Sex Marriage in the Americas, Lanham, Lexington Books, 2010, págs. 93-128. 
Código Civil, por ejemplo) establece que el matrimonio es la "unión entre el hombre y la mujer".

La Constitución del país $B$ no solo establece que "todos son iguales ante la ley", sino también que el matrimonio y la unión de hecho son uniones "entre el hombre y la mujer". Una ley ordinaria en el país $B$ (un Código Civil, por ejemplo) contiene un artículo con idéntica redacción, el cual establece que el matrimonio y la unión de hecho son uniones "entre el hombre y la mujer".

Parece plausible sostener que la Corte Constitucional del país $A$ tiene más libertad interpretativa que la del país $B$. Entre otras cosas, eso significa que la Corte Constitucional del país $A$ puede declarar más fácilmente la inconstitucionalidad e invalidad de los artículos del Código Civil que restrinjan el matrimonio y la unión de hecho a parejas de género distinto, pues puede sostener que son incompatibles con el principio constitucional de la igualdad.

Por el contrario, le resultaría difícil a la Corte Constitucional del país $B$ declarar inconstitucional e inválido un artículo del Código Civil que fuese una copia perfecta de un artículo de la propia Constitución. Si el control de la constitucionalidad de la ley significa verificar la compatibilidad de las leyes ordinarias con la constitución de un país, es difícil que haya algo más compatible que una copia exacta del texto constitucional.

Si mi suposición es correcta, entonces - por lo menos desde la perspectiva del derecho constitucional- vale la pena saber de qué manera una determinada constitución regula el tema antes de definir los caminos que se pueden seguir al buscar la igualdad ante la ley ${ }^{11}$.

Para los fines de este artículo, se puede establecer una simple clasificación de textos constitucionales en tres grandes categorías: (i) constituciones sin ninguna disposición sobre el matrimonio o la unión de hecho; (ii) constituciones con disposiciones sobre el matrimonio y/o la unión de hecho que sean neutras en lo que se refiere al género; (iii)

${ }^{11}$ La observación "desde la perspectiva del derecho constitucional" es importante aquí para enfatizar que mi objetivo no es analizar desenlaces sustantivos. Por lo tanto, desde otras perspectivas (el más obvio ejemplo sería la perspectiva de la litigación estratégica) lo que se considera legítimo puede ser muy distinto. 
constituciones con disposiciones sobre el matrimonio y/o la unión de hecho en las cuales los géneros estén expresamente determinados ${ }^{12}$. Con base en esa clasificación, es posible organizar en las dos tablas que siguen las constituciones o documentos constitucionales de los países en los que se permite el matrimonio o la unión de hecho entre personas del mismo género ${ }^{13}$ :

Tabla 1. Regulación constitucional en países que permitieron el matrimonio entre personas del mismo género.

\begin{tabular}{lll}
\hline Ninguna disposición & $\begin{array}{l}\text { Disposiciones } \\
\text { neutras } \\
\text { en lo que se refiere al } \\
\text { género }\end{array}$ & $\begin{array}{l}\text { Disposiciones } \\
\text { específicas } \\
\text { en lo que se refiere al } \\
\text { género }\end{array}$ \\
\hline $\begin{array}{l}\text { África del Sur, Argentina, } \\
\text { Bélgica, Canadá, Dinamarca, } \\
\begin{array}{l}\text { Francia, Islandia, } \\
\text { Luxemburgo, Noruega, } \\
\text { Suecia, Países Bajos, Uruguay. }\end{array}\end{array}$ & Portugal (art. 36). & España (art. 32). \\
& & \\
\hline
\end{tabular}

${ }^{12}$ Además de esas posibilidades, podría haber otras más extremas, por ejemplo una constitución que no solo contuviera disposiciones específicas respecto del género en los matrimonios, sino que también prohibiera expresamente el casamiento entre personas del mismo sexo, como es el caso de diversas constituciones estaduales en los Estados Unidos. Esa categoría, no obstante, no será considerada en este artículo.

${ }^{13}$ En las dos tablas he incluido tan solo países en los cuales el matrimonio o la unión de hecho entre personas de un mismo género son permitidos nacionalmente. Por lo tanto, han quedado excluidos los países en los que el matrimonio o la unión de hecho entre personas de un mismo género son permitidos únicamente dentro de ciertas entidades subnacionales, tal como los estados de una federación. 
Tabla 2. Regulación constitucional en países que permitieron tan solo la unión de hecho entre personas del mismo género.

\begin{tabular}{lll}
\hline Ninguna disposición & $\begin{array}{l}\text { Disposiciones neutras } \\
\text { en lo que se refiere al } \\
\text { género }\end{array}$ & $\begin{array}{l}\text { Disposiciones } \\
\text { específicas } \\
\text { en lo que se refiere } \\
\text { al género }\end{array}$ \\
\hline $\begin{array}{l}\text { Alemania, Andorra, } \\
\begin{array}{l}\text { Fustria, Croacia, Eslovenia, } \\
\text { Liechlandia, Hungría, Irlanda, } \\
\text { República Checa, Suiza. }\end{array}\end{array}$ & $\begin{array}{l}\text { Colombia (art. 42** }), \\
\text { Erasil (art.226,§3). }\end{array}$ \\
\hline
\end{tabular}

* Además de los países mencionados en esa columna, Nueva Zelandia y el Reino Unido también deberían ser mencionados como países que permitieron la unión de hecho entre personas de un mismo género. No obstante, no los he incluido en esa tabla porque en esos casos no es posible establecer una verdadera relación de jerarquía entre documentos constitucionales y las leyes ordinarias.

** La Constitución colombiana regula tanto el matrimonio como la unión marital de hecho exactamente en la misma disposición (artículo 42). Por lo tanto, es una cuestión de interpretación saber si la mención de "hombre y mujer", vinculada al concepto de matrimonio, se refiere únicamente al matrimonio o también a la unión marital de hecho. Para una breve discusión sobre esa cuestión, cfr. el voto del magistrado Araújo Rentería en la sentencia sobre la unión de hecho entre personas de un mismo género en Colombia (Sentencia 29/2009, de 29.jan.2009, disponible en <http://www.corteconstitucional.gov.co/relatoria/2009/C-029-09.htm>).

Las tablas muestran que 12 de los 14 países en los que la definición de matrimonio fue ampliada de tal forma que abarcase las parejas de un mismo género tienen constituciones sin ninguna disposición sustancial sobre el matrimonio. Por otro lado, de los países que extendieron la unión de hecho, pero no el matrimonio, a las parejas de un mismo género, 12 tienen constituciones sin ninguna disposición sobre ese tipo de unión, dos tienen disposiciones neutras en lo que se refiere al género ${ }^{14}$ y solo uno —Brasil— tiene disposiciones sobre la unión de

${ }^{14}$ Los dos países son Colombia y Ecuador. El caso de Colombia es un poco más complejo que el de Ecuador. Sobre aquel, cfr. la nota 15, arriba; sobre este último, cfr. la nota 32, abajo. 
hecho (así como sobre el matrimonio) que son específicos en lo que se refiere al género.

Las dos tablas pueden reforzar las suposiciones que afirmé más arriba. Es difícil que sea una coincidencia que todos los países que más garantizaron la protección y el tratamiento igualitario de parejas de géneros diferentes y de un mismo género tengan constituciones que no regulen el tema.

Sin embargo, se podría argumentar que la tabla 2 debilita mi suposición, ya que plantea la cuestión de por qué los países en la primera columna extendieron la definición de unión de hecho a las parejas de un mismo género, pero no la del matrimonio. En otras palabras, si la constitución guarda silencio sobre ese asunto, ¿por qué no avanzaron más, mediante la ampliación no solo de la definición de la unión de hecho, sino también de la del matrimonio?

Tal tipo de objeción, no obstante, resulta de una malinterpretación de mi suposición. No afirmo que la ausencia de regulación constitucional del matrimonio (o de la unión de hecho) fomente la ampliación de la definición de matrimonio (o de la unión de hecho) a fin de incluir a las parejas de un mismo género. Tal suposición no solo es inverosímil e ingenua, sino que sería fácilmente refutada, ya que las constituciones de la mayoría de los países donde no se permiten el matrimonio ni la unión de hecho entre personas del mismo género no contienen ninguna disposición sobre el tema. Mi argumento es algo menos ambicioso: cuanto más detalladamente el tema es regulado en la constitución, menos libertad interpretativa tienen las cortes para extender la definición de matrimonio y de unión de hecho a parejas de un mismo género.

Pero todavía se puede hacer una objeción. A pesar de que mi suposición - como acabo de sostener- no considere que los silencios constitucionales tengan un efecto fomentador, claramente atribuye algún efecto a las normas de jerarquía constitucional, pues presupone que si una constitución regula el tema minuciosamente, y lo hace de manera específica en lo que se refiere al género, hay menos margen para que las cortes extiendan la definición de matrimonio a las parejas de un mismo género. Pero si eso fuera verdad, ¿cómo se explicaría el 
caso de España, un país cuya Constitución contiene una disposición sobre el matrimonio específica en lo que se refiere al género y que, no obstante, amplió su definición de tal forma que incluyese a las parejas de un mismo género? Hablaré de ese tema más adelante ${ }^{15}$.

No ignoro el hecho de que, para muchos autores, mi suposición parece atribuir mucha importancia a la dimensión textual de la interpretación constitucional. De hecho, en el debate académico, antes e incluso después del fallo del Supremo Tribunal Federal, cualquier intento de enfatizar la carga argumentativa establecida por el artículo 226, párrafo 3 de la Constitución brasileña ("... la unión de hecho entre el hombre y la mujer...") fue rápidamente rotulado como formalismo ${ }^{16}$ o positivismo ${ }^{17}$.

Sin embargo, aunque pueda ser verdad que no toda disposición constitucional se deba interpretar con la misma literalidad en todos los casos - pues existen innumerables razones para tomar el significado de las palabras más o menos literalmente, según el contextotambién es verdad que se deben mencionar expresamente las razones por las cuales en algunos casos se toman las palabras menos literalmente. El uso indiscriminado de rótulos como "formalismo" y "positivismo" está lejos de ser suficiente.

La objeción relativa al formalismo o textualismo suena aún más fuera de lugar en el debate brasileño debido a un argumento adicional utilizado no solo en el contexto académico, sino también en el ámbito judicial. De acuerdo con la parte actora en la ADI 4277, la prevalencia del principio de la igualdad ante la ley frente a la disposición que restringe la unión de hecho a parejas de género diferente "caería por tierra si hubiera una prohibición textual a la unión entre personas del mismo

${ }^{15}$ Cfr. tópico 5.2 .

${ }^{16}$ Cfr., por ejemplo, Moreira, A.J., "We Are Family! Legal Recognition of Same-Sex Unions in Brazil", American Journal of Comparative Law, 60, 2012, págs. 1025 y 1036. En portugués, cfr. Farias, C.C. \& Rosenvald, N., Direito das familias, 2. ${ }^{a}$ ed, Río de Janeiro, Lumen Juris, 2010, pág. 64.

${ }^{17}$ Cfr., por ejemplo, Vecchiatti, P.P.I., "União estável homoafetiva e a constitucionalidade de seu reconhecimento judicial", Revista Brasileira de Direito das Famílias e Sucessões, 14, 2010, pág. 68. 
género"18. Un argumento semejante fue presentado por Sarmento: "Si hubiera una determinación constitucional expresa que excluyera la unión entre personas de un mismo género del catálogo de las entidades familiares, habría necesidad de renunciar al debate hermenéutico y recurrir al poder de reforma constitucional"19. Los propios magistrados han afirmado repetidamente que la ausencia de una disposición constitucional explícita que prohibiera que parejas de un mismo género celebraran uniones de hecho era un requisito de su fallo ${ }^{20}$.

No obstante, ¿qué ocurriría si hubiera una disposición expresa? Poco después de sostener que enfatizar la carga argumentativa establecida por el artículo 226, párrafo 3 de la C<onstitución brasileña es un tipo de formalismo, suena extraño, como mínimo, afirmar que si la disposición fuera un poco más explícita y declarase, por ejemplo, que "solo la unión de hecho entre el hombre y la mujer serán reconocidas como entidad familiar", entonces el debate no podría llevarse adelante. La inconsistencia de dicho razonamiento quedaría aún más evidente si, en lugar de "mismo género", se mencionase "diferentes religiones" o "piel de color distinto". Es decir, ¿qué se debería hacer si una constitución prohibiese expresamente el matrimonio o la unión de hecho interracial o interreligiosa? ¿Sería necesario aceptar esa premisa y aguardar tiempos mejores? ¿No sería eso un tipo de formalismo o textualismo también? ${ }^{21}$

\section{Tomar el texto en serio}

El texto es importante. Aun cuando no nos ofrezca, la mayoría de las veces, razones conclusivas y definitivas para decidir de una otra

${ }^{18} \mathrm{ADI} 4227$, petición de la procuradora general de la república, pág. 29, § 105.

${ }^{19}$ Sarmento, D., "Casamento e união estável entre pessoas do mesmo sexo: perspectivas constitucionais", en D. Sarmento et al. (eds.), Igualdade, diferença e direitos humanos, Río de Janeiro, Lumen Juris, 2008, pág. 651. Cfr. también Vecchiatti, "União estável homoafetiva", págs. 69-70.

${ }^{20}$ Cfr. por ejemplo los votos de los magistrados Gilmar Mendes (pág. 788) y Marco Aurélio Mello (pág. 820).

$184 \quad{ }^{21}$ Volveré a esos asuntos más adelante (cfr. tópico 9.2). 
forma, el texto establece límites interpretativos o deberes argumentativos. Si la Constitución brasileña no solo declara que "todos son iguales ante la ley", sino también que el matrimonio y la unión de hecho ocurren "entre el hombre y la mujer", la relación entre esas dos disposiciones debe ser adecuadamente analizada. Algunas posibilidades básicas son: (i) entre ambas disposiciones hay una relación "regla especial vs. regla general" o una relación "regla vs. principio"; (ii) ambas disposiciones son completamente independientes entre sí.

\section{V.1. Regla general vs. regla especial o principio vs. regla}

En el ámbito jurídico, el conflicto entre una regla general y una regla especial de igual jerarquía se resuelve mediante la aplicación de una metarregla formal: lex specialis derogat legi generali, es decir, la regla especial prevalece sobre la regla general. La aplicación de esa metarregla conduce a la siguiente conclusión: si una constitución establece que todos son iguales ante la ley y la misma constitución introduce una excepción a esa regla general, entonces dicha excepción es válida y aplicable. La justificación de esa metarregla es simple: resolver el conflicto de modo inverso necesariamente despojaría la regla especial de todo sentido posible. Ese tipo de relación — "regla general vs. regla especial" - es muy común en una constitución. Hay varias otras reglas en la constitución brasileña que establecen excepciones a la cláusula general de igualdad (así como a otras cláusulas generales).

Sin embargo, se podría argumentar que el caso de la unión de hecho entre personas de un mismo género no supone un conflicto entre dos reglas, sino una tensión entre un principio y una regla. No obstante, si se sigue la conceptuación de principios y reglas más difundida en los ámbitos académico y judicial brasileños - la teoría de los principios desarrollada por Robert Alexy ${ }^{22}$ - la estrategia tampoco producirá mejores resultados, por lo menos no por sí sola. Como tanto el principio (igualdad) como la regla (unión de hecho $=$ hombre y mujer)

${ }^{22}$ Cfr. Alexy, R., Theorie der Grundrechte, 2. ${ }^{a}$ ed, Frankfurt am Main, Suhrkamp, 1994. 
tienen status constitucional, la estrategia de sostener que el principio prevalece sobre la regla también despoja a esta última de todo sentido posible. Por lo tanto, es forzoso concluir que la regla prevalece sobre el principio y no a la inversa ${ }^{23}$.

Es fácil percibir que mi descripción de las dos estrategias (regla especial vs. regla general y regla vs. principio) presupone que la disposición: "se reconoce la unión de hecho entre el hombre y la mujer como entidad familiar" significa que el Estado reconoce la unión de hecho si y tan solo si es entre un hombre y una mujer. Esa es la interpretación más estricta posible del texto y necesariamente lleva a la conclusión de que cualquier acto estatal que reconozca la unión de hecho de parejas de un mismo género debería ser considerado inconstitucional. En otras palabras: ni una ley ordinaria ni un fallo judicial podrían extender ese concepto a parejas de un mismo género.

\section{V.2. Sin relación necesaria}

Aun así, todavía sería posible argumentar que el hecho de que la disposición sobre la unión de hecho (o sobre el matrimonio) en la constitución brasileña mencione "hombre y mujer" no impide la creación de otras formas de unión de hecho y matrimonio. Sin embargo, difícilmente eso se debe a las razones invocadas por incontables autores, así como por los magistrados del Supremo Tribunal Federal, en la medida en que sus argumentos se basan en la primacía del principio de la igualdad sobre la regla relativa a la unión de hecho.

Para mantener la validez y la aplicabilidad de la regla constitucional acerca de la unión de hecho ("entre el hombre y la mujer") y aun así justificar una ampliación del concepto de unión de hecho que abarcase a las parejas de un mismo género, es necesario adoptar una estrategia interpretativa diferente. De acuerdo con esa estrategia, las disposiciones constitucionales que regulan el matrimonio y la unión de hecho ("entre el hombre y la mujer") significan simplemente que

${ }^{23}$ Para el concepto de reglas como límite de principios, cfr. Alexy, Theorie der Grundrechte, pág. 258. 
el casamiento y la unión de hecho entre personas de género diferente son incuestionablemente reconocidos por el Estado y exigen que la ley ordinaria los regule. Pero esas disposiciones no impiden necesariamente la creación de otros tipos de matrimonio por la vía de la ley ordinaria ${ }^{24}$. En otras palabras, la constitución no es la única (ni necesariamente la más importante) fuente de instituciones de derecho privado. En realidad, la mayoría de esas instituciones (contratos, responsabilidad civil, fideicomiso, etc.) casi no son mencionadas en la Constitución y son directamente reguladas por el Código Civil. ¿Por qué no podría la unión de hecho entre personas de un mismo género seguir el mismo camino?

De hecho, ese fue el camino elegido por el parlamento español. Conforme se mencionó anteriormente, la Constitución española contiene una disposición sobre el matrimonio que es específica en lo que se refiere al género ${ }^{25}$. Aun así, el parlamento español aprobó una ley (Ley 13/2005) que extiende el matrimonio a parejas de un mismo género. Entre otras cosas, esa ley le añadió un párrafo al artículo 44 del Código Civil español, el cual declara que "el matrimonio tendrá los mismos requisitos y efectos cuando ambos contrayentes sean del mismo o de diferente sexo". En su exposición de motivos, el parlamento justifica su decisión exactamente de la manera que presenté arriba, es decir, mediante la afirmación de que el uso de los términos "hombre" y "mujer" en la disposición constitucional que regula el matrimonio tan solo significa que la "garantía constitucional del matrimonio tiene como consecuencia que el legislador no podrá desconocer la institución", pero que eso "no excluye en forma alguna una regulación que delimite las relaciones de pareja de una forma diferente a la que haya existido hasta el momento, regulación que dé cabida a las nuevas formas de relación afectiva" ${ }^{26}$. La constitucionalidad de dicha

${ }^{24}$ En ese sentido, cfr. Barroso, L.R., "Diferentes, mas iguais", en D. Sarmento et al. (eds.), Igualdade, diferença e direitos humanos, Río de Janeiro, Lumen Juris, 2008, pág. 688; Lobo, P.L.N., "Entidades familiares constitucionalizadas", Revista Brasileira de Direito de Familia, 12, 2002, págs. 40-55; Schulenberg, "Policy Stability without Policy", pág. 101.

${ }^{25}$ Cfr. tópico 4, arriba.

${ }^{26}$ Boletín Oficial del Estado, 2. jul. 2005, pág. 23632. 
ley —así como también la solidez de esa justificación — fue analizada por la Corte Constitucional española, que el 6 de noviembre de 2012 decidió avalarla ${ }^{27}$.

A estas alturas, sería posible que alguien argumentara que, si se debe aceptar la justificación alegada por el parlamento español, entonces la suposición que presenté arriba ${ }^{28}$ no puede establecer un efecto bloqueador sobre una disposición constitucional que regula el matrimonio de una manera específica en lo que se refiere al género. De hecho, no puede hacerlo. Mi suposición claramente sigue una lógica "cuanto más..., tanto menos", es decir "cuanto más específica sea la disposición constitucional en lo que se refiere al género, tanto menos libertad interpretativa tiene la corte". Pero aunque se entienda que una disposición acerca del matrimonio específica en lo que se refiere al género tiene un efecto bloqueador absoluto (es decir, elimina cualquier libertad interpretativa), eso no significa necesariamente que ese efecto se aplique al parlamento. En realidad, mi suposición se refiere tan solo a las cortes. Es precisamente en ese punto que la conexión entre normas e instituciones es decisiva.

\section{Hay que conectar normas e instituciones}

Tal como argumenté anteriormente, en el debate sobre el matrimonio y la unión de hecho entre personas de un mismo género, una contraposición abstracta entre parlamentos y cortes tiende a ignorar el hecho de que, entre otras cosas dependiendo de si y cómo una determinada constitución define los conceptos de matrimonio y de unión de hecho, escoger uno $u$ otro camino institucional para ampliar esas definiciones de tal modo que abarquen las parejas de un mismo género puede ser una cuestión que no permita una elección totalmente libre.

La suposición que establecí anteriormente ilustra el argumento y puede ser útil para explicar cómo y por qué el caso brasileño se ha

${ }^{27}$ El fallo puede accederse en <http://www.tribunalconstitucional.es/es/resolucionesrecientes/Documents/2005-06864STC.pdf> . 
desviado de la tendencia generalizada internacionalmente relativa al reconocimiento del matrimonio y/o la unión de hecho entre personas del mismo género. Las tablas 1 y 2 , presentadas más arriba, han sido elaboradas con el propósito de indicar las variables normativas. La tabla 3, más abajo, se refiere a los mismos países, aunque aquí están clasificados según una variable institucional definida en función de la institución que reconoció el matrimonio o la unión de hecho entre personas del mismo género ${ }^{29}$.

La tabla 3 muestra claramente que en casi todos los países en los cuales se reconoció el matrimonio o la unión de hecho entre personas de un mismo género, dicho reconocimiento se obtuvo por vía legislativa. Solo hay una excepción: Brasil ${ }^{30}$.

A estas alturas, queda claro por qué el fallo del Supremo Tribunal Federal no se puede comparar a otras experiencias internacionales sin las debidas reservas. Por un lado, en el ámbito normativo, Brasil tiene la regulación sobre matrimonio y unión de hecho más específica en lo que se refiere al género de todos los países aquí analizados. Por otro lado, en el ámbito institucional, Brasil es el único país en el cual el poder legislativo fue completamente ignorado durante todo el proceso. El Supremo Tribunal Federal no mostró ninguna señal de deferencia al legislativo. Sin embargo, en general la Corte declara tener el más profundo respeto por la separación de poderes. Analizaré esa cuestión en el próximo tópico.

${ }^{29}$ Es necesario hacer dos explicaciones sobre la tabla 3: (1) si una Corte Constitucional o suprema tan solo confirmó la constitucionalidad de una ley editada, se considera que la decisión fue tomada únicamente por el parlamento y (2) se han considerado tan solo los fallos dictados por cortes constitucionales o supremas, es decir, no se han tenido en cuenta sentencias de tribunales inferiores o de cortes subnacionales.

${ }^{30}$ Analizaré los casos intermediarios de Colombia y de África del Sur abajo. 
Tabla 3. Institución que reconoció el casamiento o la unión de hecho entre personas de un mismo género.

\begin{tabular}{llc} 
Parlamento & Parlamento y Corte & Corte \\
\hline $\begin{array}{l}\text { Alemania, Andorra, Argentina, Austria, } \\
\text { Bélgica, Canadá, Croacia, Dinamarca, }\end{array}$ & $\begin{array}{l}\text { África del Sur, } \\
\text { Colombia }\end{array}$ & Brasil. \\
$\begin{array}{l}\text { Ecuador } \\
\text { Francia, Eslovenia, España, Finlandia, }\end{array}$ & \\
$\begin{array}{l}\text { Liechtenstein, Luxemburgo, Malta, Noruega, } \\
\text { Nueva Zelandia, Países Bajos, Portugal, } \\
\text { Reino Unido, República Checa, Suecia, }\end{array}$ & \\
Suiza, Uruguay. &
\end{tabular}

* El reconocimiento de la unión de hecho en Ecuador en realidad no se debió ni a una ley ordinaria ni a un fallo judicial. La Constitución de Ecuador contiene una disposición sobre el matrimonio y otra sobre la unión de hecho. Aquella (artículo 67) utiliza los vocablos "hombre" y "mujer"; esta emplea el vocablo "personas". Además, el artículo 68 expresamente establece que tan solo las parejas de género distinto pueden adoptar hijos, lo que significa que el uso de "personas" en el artículo 68(1) es un claro reconocimiento de la unión de hecho entre personas de un mismo género. Como ese reconocimiento tuvo lugar a nivel constitucional, aquí se clasifica como una decisión parlamentar.

** En Hungría, la Corte Constitucional decidió en 1995 un caso sobre las uniones no registradas (decisión 14/1995). Pero la Corte prorrogó el juicio "para asegurar que el parlamento pueda resolver esa situación inconstitucional" (cfr. Szeibert-Erdős, O., "Same-Sex Partners in Hungary: Cohabitation and Registered Partnership", Utrecht Law Review, 4, 2008, pág. 213).

*** El caso colombiano es un poco más complejo y, por lo tanto, más difícil de clasificar en esta tabla. La Corte Constitucional estableció en 2011 que el Congreso debe legislar sobre el asunto dentro de dos años (una decisión semejante a la de la Corte Constitucional de África del Sur en el caso Fourie). En contraste, el reconocimiento de la unión de hecho entre personas de un mismo género, aunque haya sido determinado por la Corte Constitucional de Colombia, solo fue posible porque la ley ordinaria emplea términos neutros en lo que se refiere al género al regular el tema. 


\section{El Supremo Tribunal Federal y el Congreso en Brasil: un insólito caso de deferencia}

El Supremo Tribunal Federal reiteradamente declara que no tiene el poder de obligar al Congreso a legislar ${ }^{31}$. Aunque la Constitución brasileña prevea una acción directa de inconstitucionalidad específicamente diseñada para controlar la omisión legislativa, esa disposición establece que cuando el Congreso no obedece a una determinación constitucional positiva, la Corte puede tan solo declarar que existe una situación de omisión legislativa. A la luz de una opinión muy difundida sobre la teoría de la separación de los poderes, el tribunal ha siempre interpretado esa disposición de forma que no se le permita ir más allá de una mera declaración de omisión. En otras palabras, el incumplimiento por parte del Congreso en esos casos no tendría ninguna consecuencia concreta. Según ese mismo entendimiento acerca de la teoría de la separación de los poderes, la Corte sostiene que carece de poder para establecer un plazo para la promulgación de la legislación en cuestión.

En el caso de la unión de hecho entre personas del mismo género, la Corte, por un lado, se ha apegado a su doctrina (retórica) de deferencia: no impone ninguna medida coercitiva para el cumplimiento de sus fallos o siquiera un plazo para que el Congreso legisle. Sin embargo, por otro lado, con base en una paradójica alteración de su muy peculiar opinión acerca de la deferencia, la Corte, sin más ni menos, decidió regular el tema por sí sola, con lo que ignoró por completo al Congreso. Es muy difícil entender una interpretación acerca de la deferencia y de la teoría de la separación de los poderes según la cual una Corte no puede imponerle al Congreso la obligación de legislar ni tampoco puede establecer un plazo para que legisle, pero puede, por sí sola, hacer todo aquello que, según su propio entendimiento sobre la teoría de la separación de los poderes, le compete al Congreso.

La respuesta típica a esa crítica es muy simple: por tratarse de una cuestión relativa a derechos fundamentales, la sociedad no puede

${ }^{31}$ Cfr., por ejemplo, MI670 (2009) y MI708 (2009). 
aguardar eternamente en el supuesto de que la institución competente (el Congreso Nacional) permanezca pasiva e inerte ${ }^{32}$. Con base en el mismo entendimiento, esa omisión es inconstitucional y fundamenta la legitimidad de la Corte para actuar por sí sola, tal como lo hizo el Supremo Tribunal Federal. Sin embargo, esa justificación tan solo enfrenta — si es que se puede decir que lo haga - la objeción institucional, pero no la textual, ni la combinación de ambas.

Como se analizó arriba, si una constitución declara que todos son iguales ante la ley y, al mismo tiempo, establece que la unión de hecho se forma entre un hombre y una mujer, tal hecho puede interpretarse al menos de dos maneras: (1) una regla especial introdujo una excepción a la regla general (o la regla constitucional limitó la amplitud del principio constitucional), o sea, que aunque todos sean iguales ante la ley, solo las parejas de género diferente pueden formar una unión de hecho, y (2) el hecho de que la disposición sobre la unión de hecho en la Constitución brasileña mencione "hombre y mujer" no constituye un impedimento a la creación de otras formas de unión y de matrimonio. Como mostré arriba, de acuerdo con la segunda interpretación, el uso de los vocablos "hombre" y mujer" en las disposiciones constitucionales que regulan el matrimonio y la unión de hecho implica tan solo que el matrimonio y la unión de hecho entre personas de género diferente son incuestionablemente reconocidos por el Estado y exigen que las leyes ordinarias los regulen. Pero esas disposiciones no impiden necesariamente la creación de otros tipos de matrimonio por la vía de la ley ordinaria. En ese punto, la conexión entre normas, interpretación e instituciones es decisiva.

De acuerdo con la primera interpretación, el parlamento, en calidad de legislador ordinario, no puede actuar, y eso se debe a una razón formal y jerárquica: las leyes ordinarias no pueden alterar las normas constitucionales. A su vez, si el parlamento no puede actuar, menos aún lo pueden las cortes. De esa forma, la única autoridad legítima que puede alterar el status quo sería aquella que la propia 
constitución considera competente para enmendar la constitución (en el caso de Brasil, $3 / 5$ del Congreso Nacional).

De acuerdo con la segunda interpretación, el Congreso Nacional, en calidad de órgano legislativo legitimado democráticamente, puede crear nuevas formas de matrimonio y de unión de hecho. En ese contexto, la cuestión que se debe responder es si una Corte Constitucional tiene la misma autoridad y legitimidad, y si por ese motivo está autorizada a ignorar al parlamento. E1 Supremo Tribunal Federal claramente se consideró tan legitimado como el Congreso. Pero la justificación de la Corte se basa en un non sequitur. En otras palabras, aun si se supone que la referencia a "hombre y mujer" en la constitución es tan solo un ejemplo de una posible unión de hecho, y no una característica exigida de todas las uniones de hecho, eso no revela absolutamente nada acerca de la posibilidad de crear otras formas de unión de hecho por medio de fallos judiciales ${ }^{33}$. Dicha construcción exige argumentos adicionales. Es difícil encontrar, en los votos de los magistrados que dictaron el fallo, un argumento sólido, es decir, un argumento que vaya más allá de la idea ingenua de que "alguien tiene que hacer algo" 34 .

Ese argumento, por si solo simplista y criticable, podría admitirse, desde la perspectiva del derecho constitucional, solo si fuera imposible constreñir al Congreso a legislar. Es aquí que entra en juego el derecho comparado.

${ }^{33}$ Son buenos ejemplos del razonamiento basado en el non sequitur los que se encuentran en los votos de los magistrados Ricardo Lewandowski y Cezar Peluso. Los dos argumentaron que los tipos de familia establecidos en la Constitución son ejemplos tan solo (Lewandowski, pág. 716), no numerus clausus (Peluso, pág.874). Por lo tanto, la Corte puede crear otros tipos de familia. Queda evidente que ambos extrajeron una conclusión relativa a la institución directamente de un argumento tan solo substantivo. Argumentos semejantes pueden ser encontrados también en la doctrina (cfr. las referencias en la nota 26 , arriba).

${ }^{34} \mathrm{El}$ argumento "alguien tiene que hacer algo" puede ser encontrado en varios de los votos del fallo. Cfr., por ejemplo, los votos de los magistrados Gilmar Mendes (pág. 730) y Celso de Mello (pág. 867). 


\section{Lecciones de derecho comparado}

El Supremo Tribunal Federal es extremadamente abierto al uso de fallos de tribunales extranjeros para construir argumentos en sus procesos decisorios. Probablemente pocas cortes en el mundo citen más fallos extranjeros que el Supremo Tribunal Federa ${ }^{35}$. De forma bastante atípica, en el fallo acerca de la unión de hecho entre personas de un mismo género, esa tendencia no está presente ${ }^{36}$. Una Corte que cita fallos de otros países tan frecuentemente podría haberse beneficiado mucho del recurso a fallos de otros países como herramienta argumentativa. En particular, los fallos de las cortes constitucionales de África del Sur y de Colombia podrían haber ofrecido un interesante aporte a esa cuestión.

La experiencia de África del Sur es muy conocida. En el fallo del caso Fourie ${ }^{37}$, la Corte Constitucional de África del Sur declaró que tanto la definición de matrimonio del common law como la sección 30(1) del Marriage Act de 1961 eran inconsistentes con la Constitución y por consiguiente inválidas. Sin embargo, la Corte decidió suspender esas declaraciones de invalidez por 12 meses para "permitir que el parlamento apruebe las leyes apropiadas" 38 . Y el Parlamento lo hizo dentro de los 12 meses establecidos por la corte. Como resultado de esa actitud de deferencia, la decisión de reconocer el matrimonio entre personas del mismo género en África del Sur, aunque haya sido impulsada por un fallo de la Corte, fue tomada por el Parlamento, después de un intenso debate popular ${ }^{39}$.

${ }^{35}$ Para algunas estadísticas al respecto, cfr. Silva, V.A., "Integração e diálogo constitucional na América do Sul", en A. v. Bogdandy et al. (eds.), Direitos humanos, democracia e integração jurídica na América do Sul, Río de Janeiro: Lumen Juris, 2010, págs. 515-530.

36 Únicamente el magistrado Gilmar Mendes citó brevemente algunos ejemplos de derecho comparado (de Dinamarca, de los Países Bajos y de Alemania).

${ }^{37}$ Minister of Home Affairs and Another v Fourie and Another (CCT60/04) [2005].

${ }^{38}$ Ibídem, pág. 18.

${ }^{39}$ Para un buen análisis de todo el proceso judicial y legislativo que resultó a la adopción del Civil Union Act en África del Sur, cfr., por ejemplo, De Vos, P. \& Barnard, J., "Same-Sex Marriage, Civil Unions and Domestic Partnerships 
En Colombia, un fallo dictado por la Corte Constitucional en $2009^{40}$ extendió a las parejas del mismo género la mayoría de los derechos asegurados a las parejas de género diferente que conviven. La Corte interpretó que ciertas expresiones neutras en lo que se refiere al género - como "cónyuge", "compañero" o "compañera permanente"-, usadas en muchas leyes ordinarias, son aplicables tanto a parejas de género diferente como a parejas del mismo género. E1 fallo no afecta el concepto de matrimonio, que permaneció limitado a las parejas de géneros diferentes. La justificación para extender tan solo el concepto de unión de hecho, pero no el de matrimonio, es tan directa como la lógica del presente artículo: tanto la constitución como las leyes ordinarias usan vocablos específicos en lo que se refiere al género (hombre y mujer) para la regulación del matrimonio.

Es aún más interesante, dados los objetivos del presente artículo, el fallo posterior sobre el matrimonio entre personas del mismo género. En julio de 2011, la Corte Constitucional de Colombia, aunque mantuviera su interpretación anterior - en función del hecho de que tanto el texto de la constitución como el del Código Civil definen el matrimonio como la unión entre el hombre y la mujer-, exhortó al Congreso para que, antes del 20 de junio de 2013, "legisle, de manera sistemática y organizada, sobre los derechos de las parejas del mismo sexo con la finalidad de eliminar el déficit de protección que, según los términos de esta sentencia, afecta a las mencionadas parejas" 41 . Además, la corte

in South Africa", South African Law Journal, 124, 2007, págs. 795-826; De Vos, P., "A Judicial Revolution? The Court-Led Achievement of SameSex Marriage in South Africa", Utrecht Law Review, 4, 2008, págs. 162-174. Cfr. también Bilchitz, D. \& Judge, M. "For Whom Does the Bell Toll? The Challenges and Possibilities of the Civil Union Act for Family Law in South Africa", South African Journal on Human Rights, 23, 2007, págs. 466-499.

${ }^{40}$ Sentencia C-029/2009, de 28 de enero de 2009.

${ }^{41}$ Corte Constitucional de Colombia, Sentencia C-577/2011. Para un análisis de la jurisprudencia reciente de la Corte Constitucional de Colombia sobre el matrimonio y la unión de hecho entre personas de un mismo género, así como sobre la difícil relación entre la Corte, el Gobierno y el Parlamento sobre esa cuestión, cfr. Nagle, L.E., "Giving Shelter from the Storm: Colombians Fleeing Persecution Based on Sexual Orientation", Tulsa Law Review, 48, 
decidió que "[s]i el 20 de junio de 2013 el Congreso de la República no ha expedido la legislación correspondiente, las parejas del mismo sexo podrán acudir ante notario o juez competente a formalizar y solemnizar su vínculo contractual" 42 . En esa decisión, lo que estaba en juego no era la definición o el uso del término matrimonio en sí. La Corte no solo se refirió a un "vínculo contractual", y no al matrimonio, sino que tampoco exhortó al Congreso a extender el uso del término matrimonio a las parejas del mismo género. En realidad, lo que estaba en juego aquí era la posibilidad de construir una familia, ya que, de acuerdo con la jurisprudencia de las cortes colombianas, solo el matrimonio (exclusivamente de parejas de género diferente, por lo tanto) constituye una familia. Ese era el déficit de protección que la Corte insistía que fuera eliminado. El Congreso colombiano no cumplió lo exigido, es decir, no legisló de manera sistemática sobre los derechos de las parejas de un mismo género. Ante esa actitud, la sentencia comenzó a producir los efectos preestablecidos. Aun así, tal como la Corte de África del Sur, la Corte colombiana no ignoró al parlamento.

\section{IX. ¿Cuál es el problema causado por el atajo institucional?}

A estas alturas, sería posible preguntarse cuál es el problema causado por el atajo institucional (institutional bypass) que describí arriba. Si el resultado es el mismo, ¿por qué debe la Corte aguardar la acción del Congreso? ¿Es relevante quién decide? ¿O es tan solo la expresión de alguna concepción anticuada de separación de poderes? ¿No sería anacrónico insistir en preguntar si las cortes tienen legitimidad para tomar ese tipo de decisiones? Primordialmente, sería posible

2012, pág. 13. Cfr. también Universidad de Los Andes Public Interest Law Group, "National Report: Colombia", Journal of Gender, Social Policy \& the Law, 19, 2011. En español, cfr. Sarmiento, J.P., "La modulación de sentencias como medio para articular la oportunidad política de la Corte Constitucional colombiana: El caso de las parejas del mismo sexo", Revista de Derecho, 37, 2012, pág. 302; Ruiz, P.A.C. et al., "El Reconocimiento de derechos a las parejas del mismo sexo", Revista Estudios Socio-Jurídicos, 14, 2012.

${ }^{42}$ Corte Constitucional de Colombia, Sentencia C-577/2011. 
argumentar que debe haber algún momento a partir del cual se convierte en disimulación devolverle todo al legislativo, especialmente cuando a este no le queda prácticamente ninguna opción. En tales casos, ¿no sería más honesto que la Corte decidiera por sí sola de una vez?

Esas cuestiones son más que legítimas. De hecho, muchas de ellas fueron repetidamente suscitadas en Brasil antes y después del fallo del Supremo Tribunal Federal en el caso de la unión de hecho entre personas de un mismo género. Trataré de responder esas cuestiones en los tópicos que siguen, al analizar los argumentos con base en el tiempo, el resultado y la equidad.

\section{IX.1. Tiempo}

Un argumento relacionado al tiempo ha sido frecuentemente invocado para justificar la estrategia del atajo (bypass) adoptada por el Supremo Tribunal Federal. Tal argumento cita la urgencia por resolver el problema. En la medida en que tener una actitud deferente implica conceder más tiempo para que el Congreso actúe, frecuentemente se sostiene que, si el resultado final es el mismo, aguardar la elaboración de leyes atrasa innecesariamente la posibilidad del ejercicio de iguales derechos por parejas de un mismo género. Pero ese argumento no convence. En África del Sur, transcurrieron aproximadamente dos años desde la llegada del caso Fourie a la Corte Constitucional hasta la aprobación de la ley por el parlamento. En Brasil, las parejas de un mismo género tuvieron que esperar más de tres años entre la presentación de la acción ante el Supremo Tribunal Federal y el fallo definitivo ${ }^{43}$. El caso bien demuestra la inadecuación del argumento "no podemos aguardar eternamente", que dominó la discusión en Brasil. El argumento supone una perspectiva binaria sin fundamento según la cual o bien la Corte decide por sí sola o tendremos que esperar para siempre. La experiencia de África del Sur demuestra que hay alternativas.

${ }^{43}$ Un "fallo definitivo" que dejó varios interrogantes sin respuesta. En otras palabras, para algunas cuestiones (como matrimonio y adopción) el fallo definitivo todavía no se ha dictado. 


\section{IX.2. Resultado: el aspecto simbólico}

Sin embargo, todavía existe un argumento aún más fuerte para no contornear al Congreso: el valor simbólico de una decisión legislativa. En lo que toca al sistema jurídico, Brasil es un país de tradición continental europea. Aunque las diferencias entre el civil law (derecho continental) y el common law se hayan vuelto más tenues en muchos aspectos, por lo menos en un punto las diferencias entre ellos todavía son relevantes: el valor simbólico de la legislación. Mantener el texto del Código Civil brasileño intacto tiene un valor simbólico (negativo) que no se debe subestimar. En un país del civil law, hay dimensiones simbólicas e incluso educativas inherentes a las palabras de la ley. En Brasil, las ediciones impresas y online de la legislación no suelen hacer mención de los fallos judiciales. Eso significa que, hoy en día y más adelante, cualquiera que adquiera un ejemplar del Código Civil, o que lo lea online, observará que el matrimonio y la unión de hecho ocurren únicamente "entre el hombre y la mujer", ya que el texto no habrá sido alterado (ni podría serlo) por el Supremo Tribunal Federal. Al escoger ignorar al Congreso, la Corte simplemente pasó por alto ese aspecto simbólico.

\section{IX.3. Insinceridad}

Aún subsiste la objeción según la cual sería mera disimulación devolverle la tarea al legislativo si a este no le queda prácticamente ninguna posibilidad de opción. Esa objeción tampoco es convincente. Especialmente cuando se trata de derechos fundamentales, el combate a la inercia del Congreso por medio del establecimiento de un deber de legislar y de la fijación de un plazo para que el Congreso legisle (en vez de decidir todo por sí sola) puede producir por lo menos dos resultados positivos.

En primer lugar, únicamente una decisión tomada por el legislativo puede alterar el texto de las leyes, lo que llevaría al significativo efecto simbólico mencionado arriba.

En segundo lugar, obliga al Congreso a discutir lo que está en juego: aunque el margen de decisión y discrecionalidad atribuido al 
Congreso pueda ser, en ciertos casos, considerablemente limitado, el legislativo no puede hacer oídos sordos indefinidamente a las demandas sociales solo porque se refieren a temas moralmente delicados y, en consecuencia, políticamente arriesgados. Últimamente, diputados y senadores han evitado temas política y moralmente controvertidos para no vincularse a una sola posición y, de esa forma, no perder electores. Al adoptar esa postura, aquellos que han sido elegidos para decidir cuestiones política y moralmente relevantes para el país son precisamente los que han dejado de cumplir su papel, lo que ha hecho que sea el Supremo Tribunal Federal quien lo ejerza cada vez más. Es perfectamente comprensible que la litigación estratégica de los derechos humanos concentre sus esfuerzos exclusivamente en el resultado deseado. Pero lo mismo no se aplica a aquellos cuya función es discutir no solo los resultados, sino también el buen funcionamiento de las instituciones políticas y jurídicas en una democracia. Para estos últimos, aceptar la omisión del Poder Legislativo solo porque alguien (el Supremo Tribunal Federal) ha asumido parte de sus funciones significa permitir la gradual erosión de la democracia representativa. Si al decidir un asunto moralmente relevante como el matrimonio de personas de un mismo género es posible involucrar a todos los poderes estatales e incluso a la sociedad civil, entonces no hay argumentos convincentes para aceptar que un único poder, y justamente aquel que menos admite la participación popular —el Poder Judicial—, decida todo por sí solo.

\section{IX.4. Teorías de la interpretación y separación de los poderes}

A lo largo de este artículo, he formulado varias objeciones al fallo del Supremo Tribunal Federal, con base tanto en argumentos de carácter institucional como en argumentos relativos al texto constitucional. He sostenido reiteradamente que el texto es importante, así como las instituciones. Al argumentar que el texto es importante, no estoy defendiendo ningún tipo específico de teoría de la interpretación. Lo que exijo es mucho más directo y menos ambicioso: no podemos ignorar el texto constitucional. En otras palabras, no podemos fingir que no 
hay un texto. Debe haber una diferencia — no importa cuán tenueentre tener una disposición constitucional que declara que el matrimonio y la unión de hecho existen entre un hombre y una mujer y no tener ninguna disposición constitucional al respecto. Como quedó claro a lo largo del artículo, es posible argumentar que esa disposición constitucional no imposibilita la extensión del matrimonio y de la unión de hecho a parejas de un mismo género, pero establece una carga argumentativa que no puede ser ignorada. En este artículo he argumentado que es posible desarrollar una línea de razonamiento que tome esa carga argumentativa en serio y aun así alcance el mismo (o mejor) progreso sustancial con respecto a la protección igualitaria ante la ley para parejas de un mismo género.

En cuanto al aspecto institucional, tampoco estoy defendiendo algún tipo específico de teoría de la separación de los poderes. No es verdaderamente relevante para los fines de este artículo la interminable discusión sobre la legitimidad del derecho creado por los jueces. Las razones aducidas en el artículo no dependen de ese debate. Simplemente supuse que una decisión tomada por la Corte $y$ por el Congreso es, por varias razones, mejor que una decisión tomada por la Corte por sí sola, especialmente - aunque no únicamente-porque la Corte es incapaz de tomar una decisión que sistematice la cuestión, porque la Corte no puede alterar el texto de la ley y porque el atajo institucional (institutional bypass) descrito arriba solo contribuye para agravar la inercia, la indiferencia y la insensibilidad del legislativo con relación a asuntos moralmente relevantes pero políticamente arriesgados.

\section{Conclusión}

En este artículo he pretendido mostrar que, aunque haya alcanzado importantes e innegables progresos sustantivos, el fallo del Supremo Tribunal Federal sobre la unión de hecho entre personas del mismo género suscita diversas objeciones formales y procedimentales. Se podría argumentar que ese sacrificio es inevitable. Ese argumento en general sigue la siguiente fórmula: para alcanzar algún progreso en 
la garantía de la igualdad, fue necesario ignorar algunas cuestiones formales y procedimentales. Pero ese argumento no es sólido.

A lo largo de este texto, además de describir las cuestiones problemáticas formales y procedimentales, también procuré demostrar que la idea de un sacrificio institucional inevitable no es necesariamente aplicable. Frecuentemente, esa idea se expresa a partir de frases como "no podemos aguardar para siempre" o "alguien tiene que hacer algo". He intentado demostrar que una decisión fomentada por la Corte, pero tomada por el parlamento (como en África del Sur), puede ser más rápida, más completa y sistemática, más legítima e incluso sustancialmente más avanzada que el fallo del Supremo Tribunal Federal.

Como el Supremo Tribunal Federal fue incapaz de decidir esa cuestión tan compleja de manera sistemática, tuvo que concentrarse únicamente en una cuestión binaria ingenuamente simple: sí o no a la unión de hecho de personas de un mismo género. Cualquier detalle que vaya más allá de esa decisión binaria (por ejemplo, la conversión de la unión de hecho en casamiento y sobre todo la adopción) no ha sido definido. No porque fuera poco importante, sino en función de las particularidades del proceso decisorio del Supremo Tribunal Federal.

Así, queda aún más claro que lo que está en juego aquí no es solo una concepción anticuada de la separación de los poderes. En realidad, una concepción tradicional de la separación de poderes sería absolutamente incompatible con la tesis central de este artículo: que la Corte debería haber establecido un plazo para que el Congreso legislara al respecto.

En conclusión, puedo tan solo repetir que el texto es importante. Y que las instituciones también son importantes. Si el Supremo Tribunal Federal lo hubiese tomado en serio y no se hubiera negado a establecer un diálogo con el Congreso Nacional, el desenlace probablemente habría sido mucho mejor para la Corte en sí, para el congreso, para la sociedad civil como un todo y especialmente para las parejas de un mismo género, que aún hoy no tienen los mismos derechos atribuidos a las parejas de género diferente. 
Virgílio Afonso da Silva

\section{Bibliografía}

Alexy, R., Theorie der Grundrechte, 2. ${ }^{\mathrm{a}}$ ed., Frankfurt am Main: Suhrkamp, 1994.

Barroso, L. R., "Diferentes, mas iguais: o reconhecimento jurídico das relações homoafetivas no Brasil", Igualdade, diferença e direitos humanos, Río de Janeiro: Lumen Juris, 2008, págs. 661-693.

Bilchitz, D. \& Judge, M., "For Whom Does the Bell Toll? The Challenges and Possibilities of the Civil Union Act for Family Law in South Africa", South African Journal on Human Rights 23, 2007, págs. 466-499.

Ceballos Ruiz, P. A., Ríos Quintero J.V., \& Ordoñez Patiño, R., "E1 Reconocimiento de derechos a las parejas del mismo sexo: El camino hacia un concepto de familia pluralista", Revista Estudios Socio-Jurídicos 14:2, 2012, págs. 207-239.

De Vos, P., "A Judicial Revolution? the Court-Led Achievement of Same-Sex Marriage in South Africa", Utrecht Law Review 4:2, 2008, págs.162-174.

De Vos, Pierre \& Jaco Barnard. "Same-Sex Marriage, Civil Unions and Domestic Partnerships in South Africa: Critical Reflections on an Ongoing Saga", South African Law Journal 124, 2007, págs. 795-826.

Farias, C. C., \& Rosenvald, N., Direito das famílias, 2. ${ }^{\text {a }}$ ed., Río de Janeiro: Lumen Juris, 2010.

Lobo, P. L. N., "Entidades familiares constitucionalizadas: para além do numerus clausus", Revista Brasileira de Direito de Família 12, 2002, págs. 40-55.

Moreira, A. J., "We Are Family! Legal Recognition of Same-Sex Unions in Brazil", American Journal of Comparative Law 60:4, 2012, págs. 1003-1042.

Nagle, L. E., "Giving Shelter from the Storm: Colombians Fleeing Persecution Based on Sexual Orientation", Tulsa Law Review 48, 2012, págs.1-26.

Sarmento, D., "Casamento e união estável entre pessoas do mesmo sexo: perspectivas constitucionais", en Daniel Sarmento, Daniela 
Ikawa \& Flávia Piovesan (orgs.), Igualdade, diferença e direitos humanos, Río de Janeiro: Lumen Juris, 2008, págs. 619-659.

Sarmiento, J. P., "La modulación de sentencias como medio para articular la oportunidad política de la Corte Constitucional colombiana: El caso de las parejas del mismo sexo", Revista de Derecho 37, 2012, págs. 283-320.

Schulenberg, S., "Policy Stability without Policy: The Battle over Same-Sex Partnership Recognition in Brazil", en Jason Pierceson, Adriana Piatti-Crocker \& Shawn Schulenberg (orgs.), Same-Sex Marriage in the Americas: Policy Innovation for Same-Sex Relationships, Lanham: Lexington Books, 2010, págs. 93-128.

Silva, V. A., "Deciding Without Deliberating", International Journal of Constitutional Law 11, 2013, págs. 557-584.

—. "Integração e diálogo constitucional na América do Sul", en Armin von Bogdandy, Flávia Piovesan \& Mariela Morales Antoniazzi (orgs.), Direitos humanos, democracia e integração jurídica na América do Sul, Río de Janeiro: Lumen Juris, 2010, págs. 515-530. . "Supremo Tribunal Federal", en Eduardo Ferrer Mac-Gregor (org.), Crónica de tribunales constitucionales en Iberoamérica, Buenos Aires/México: Marcial Pons/UNAM, 2009, págs. 85-106.

Szeibert-Erdős, O., "Same-Sex Partners in Hungary: Cohabitation and Registered Partnership", Utrecht Law Review 4:2, 2008, págs. 212-221.

Universidad de Los Andes Public Interest Law Group. "National Report: Colombia", Journal of Gender, Social Policy \& the Law 19:1, 2011, págs. 97-112.

Vecchiatti, P. R. I., "União estável homoafetiva e a constitucionalidade de seu reconhecimento judicial", Revista Brasileira de Direito das Famílias e Sucessões 14, 2010, págs. 66-88. 